\title{
CONTABILIDADE GERENCIAL: PERCEPÇÃO DOS GESTORES DE MICRO E PEQUENAS EMPRESAS
}

MANAGEMENT ACCOUNTING: PERCEPTION OF MICRO AND SMALL BUSINESS MANAGERS

Recebido em 25.03.2020 Aprovado em 15.04.2020

Avaliado pelo sistema double blind review

DOI: https://doi.org/10.32888/cge.v8i1.41160

\author{
Ranjel Riedi \\ ranjel@unochapeco.edu.br \\ Universidade Comunitária da Região de Chapecó - Chapecó/Santa Catarina, Brasil \\ http://orcid.org/0000-0003-2449-5880
}

\section{Raphael Martini}

raphaelmartini@unochapeco.edu.br

Universidade Comunitária da Região de Chapecó - Chapecó/Santa Catarina, Brasil

http://orcid.org/0000-0002-6764-4949

\section{Diones Kleinibing Bugalho}

diones.bugalho@unochapeco.edu.br

Universidade Comunitária da Região de Chapecó - Chapecó/Santa Catarina, Brasil

https://orcid.org/0000-0002-4636-5086

\section{Francieli Morlin Bugalho}

fran morlin@hotmail.com

Universidade Federal de Santa Catarina - Florianópolis/Santa Catarina, Brasil

http://orcid.org/0000-0003-2449-5880

\section{Resumo}

O objetivo consiste em analisar a percepção dos gestores em relação a utilização da contabilidade gerencial em micro e pequenas empresas como ferramenta que pode auxiliar na tomada de decisão. Os procedimentos metodológicos caracterizam como descritiva, de levantamento e quantitativa. Os resultados evidenciam que $65 \%$ das empresas indicam a questão financeira como elemento primordial, enquanto que $73 \%$ mencionam que a contabilidade gerencial é uma importante ferramenta de controle, e $90 \%$ conhecem seus os benefícios, além disso, todos os respondentes afirmam que gostariam de utilizar mais ferramentas de contabilidade gerencial em suas empresas, enquanto que apenas $49 \%$ a utiliza para tomada de decisões.

Palavras-chave: Contabilidade gerencial. Micro e pequena empresa. Tomada de decisão.

\begin{abstract}
The objective is to analyze the perception of managers in relation to the use of management accounting in micro and small companies as a tool that can assist in decision making. The methodological procedures characterize it as descriptive, survey and quantitative. The results show that $65 \%$ of the companies indicate the financial issue as a key element, while $73 \%$ mention that management accounting is an important control tool, and $90 \%$ know its benefits, in addition, all respondents say they would like to use more management accounting tools in their companies, while only $49 \%$ use it for decision making.
\end{abstract}

Keywords: Management accounting. Micro and small business. Decision making. 


\section{Introdução}

Atualmente as pequenas e médias empresas sofrem com diversas mudanças organizacionais, que consequentemente faz com que necessitem de ferramentas e informações contábeis, que possam auxiliá-las em suas decisões gerenciais acerca de que essas lhes sirvam de base para melhor administração da empresa e dar suporte em suas decisões (CALLADO; MELLO, 2018).

Nesse sentido, a contabilidade gerencial é o ramo da contabilidade que pode fornecer informações aos administradores das empresas, auxiliando na tomada de decisões, bem como em funções gerenciais. Esta ferramenta vem se tornando cada vez mais decisiva numa gestão empresarial, e muitas vezes os profissionais além de fornecer informações, assumem um papel ativo no dia a dia da empresa em suas decisões e estratégias as quais ela enfrenta (CREPALDI, 2011)

A contabilidade gerencial é um conjunto de práticas e técnicas destinadas a fornecer aos gestores informações financeiras, para ajudá-los a tomar decisões e manter um controle eficaz sobre os recursos da empresa, e no Brasil as micros e pequenas empresas mostram grande relevância econômica priorizando ainda mais o papel da contabilidade gerencial (VAZ; ESPEJO, 2015).

O principal papel da contabilidade gerencial nas empresas pode ser entendido como aumentar o conhecimento organizacional, fazendo com que isso diminua o risco de erros nas tomadas de decisões. Magro, Silva e Klann (2017) descrevem que nesse aspecto ela é a principal ação que determina o rumo das atitudes a serem tomadas nas empresas trazendo muitos benefícios para a organização.

Entretanto, a falta de estudos direcionados à contabilidade gerencial que demonstrem sua importância na gestão, faz com que seus gestores muitas vezes não conheçam as vantagens que podem ser obtidas para a empresa, e com a competitividade atual a contabilidade gerencial tem se tornado o principal foco nas organizações para atingir seus objetivos (FERNANDES; GALVÃO, 2016).

Muitas medias e pequenas empresas não usam ou não conhecem nenhum tipo de informação para tomadas de decisões acabando as vezes errando em suas atividades contábeis ou até mesmo na administração. Diante deste contexto, tem-se o seguinte problema de pesquisa: Avaliar a percepção dos gestores das micro e pequenas empresas em relação a utilização da contabilidade gerencial. A partir deste problema foi elaborado o objetivo da pesquisa que consiste em analisar a percepção dos gestores em relação a utilização da contabilidade gerencial em micro e pequenas empresas.

A pesquisa justifica-se em gerar conhecimento e informações sobre contabilidade gerencial nas micro e pequenas empresas, que possam auxiliar seus gestores na utilização dessas informações para melhor administração da empresa, vem como ajudá-los nas tomadas de decisões com o intuito de que essas empresas não cometam erros e consigam diminuir os riscos de prejuízos, para que futuramente elas tenham os lucros planejados e alcancem seus objetivos (ALMEIDA; PERREIRA; LIMA, 2016).

Esse estudo está subdivido em 5 partes, iniciando com a introdução, em seguida a revisão da literatura, que visa expor informações sobre a contabilidade gerencial em micro e pequenas empresas, na terceira parte se encontra a metodologia da pesquisa, na quarta encontra-se a análise e interpretação dos resultados e pôr fim a quinta parte com as conclusões.

\section{Referencial teórico}

A revisão da literatura apresenta os conceitos que sustentam o assunto pesquisado e serve de base para análise dos dados coletados. A importância da contabilidade gerencial das empresas apresenta os benefícios almejados com a utilização desse artefato pelas micro e pequenas empresas, independentemente do tamanho da empresa é preciso 
ter um controle gerencial para auxiliar na tomada de decisão. E, finalmente, a subseção de estudos correlatos apresenta resultados já obtidos em investigações de natureza similar.

\section{Micro e Pequenas Empresas (MPEs)}

O principal meio de identificar o tamanho de uma empresa, ou seja, saber se ela é microempresa (ME) ou pequena empresa (EPP) é através do seu faturamento anual, conforme o artigo $3^{\circ}$ da lei complementar 123/2006 microempresas são:

[...] consideram-se microempresas ou empresas de pequeno porte, a sociedade empresária, a sociedade simples, a empresa individual de responsabilidade limitada [...], desde que:

I - no caso da microempresa, aufira, em cada ano-calendário, receita bruta igual ou inferior a R\$ 360.000,00 (trezentos e sessenta mil reais); e

II - no caso da empresa de pequeno porte, aufira, em cada ano calendário, receita bruta superior a $\mathrm{R} \$ 360.000,00$ (trezentos e sessenta mil reais) e igual ou inferior a $\mathrm{R} \$ 4.800 .000,00$ (quatro milhões e oitocentos mil reais) [...].

As micro e pequenas empresas possuem um tratamento diferenciado e favorecido, ao qual está amparado pelo estatuto das micro e pequenas empresas em âmbito Federal, Estadual e Municipal. O estatuto das micro e pequenas empresas foi instituído pela Lei Complementar 123 de 14 de dezembro 2006, a qual revoga a lei 9.841 de 5 de outubro de 1999, antigo estatuto das micro e pequenas empresas.

O artigo $1^{\circ}$ da Lei Complementar 123/2006, as micro e pequenas empresas são beneficiadas por terem um tratamento diferenciado e favorecido, onde um desses tratamentos consiste no recolhimento unificado dos impostos e contribuições devidos a União, Estados, Distrito Federal e Municípios.

Um fator relevante é que as micro e pequenas empresas tem papel fundamental na economia brasileira, onde são responsáveis por empregar uma grande parte da mão de obra urbana e ainda representam $98 \%$ do número de empresas formais no Brasil, onde a cada ano este segmento vem crescendo e contribuindo para a economia brasileira e ainda a participação das micro e pequenas empresas brasileiras somadas representa $27 \%$ de todo o Produto Interno Bruto (PIB) do Brasil (SEBRAE, 2014).

Santos et al. (2017) investigaram o perfil de tomada de decisão dos gestores de arranjos produtivos locais (maioria microempresas) de confecção em Pernambuco. Observaram que, frequentemente, os gestores utilizam-se, total ou parcialmente, de fatores subjetivos na tomada de decisões. Os autores sugeriram maior aprofundamento sobre como as empresas utilizam as ferramentas contábeis e gerenciais.

Fiek e Loose (2017) ressaltam que as micro e pequenas empresas tem o seu espaço na economia brasileira, e vem sendo reconhecidas pelo poder público devido ao seu grande impacto econômico e de desenvolvimento. Os autores destacam ainda, que esse reconhecimento por parte do poder público, aumentou os planos para estruturar as políticas públicas para as micros e pequenas empresas há mais de 45 anos, mas somente em um período recente essas empresas passaram a receber atenção compatível com sua participação na economia.

Fiek e Loose (2017) ainda mencionam que o primeiro programa criado para beneficiar as micro e pequenas empresas foi datado em 1960, instituído pelo Banco Nacional do Desenvolvimento Econômico (BNDE), onde ampliava e facilitava a linha de crédito para financiamento para as pequenas e médias empresas (PMEs). Por meio desse programa surgiu em 1964, o grupo Executivo do Programa de Financiamento à Pequena e Média Empresa (Fipeme), onde oferecia às pequenas e médias empresas uma linha de crédito com maiores prazos e menores taxas, cujo objetivo era de facilitar a aquisição de máquinas e equipamentos de trabalho e ao mesmo tempo incentivar o desenvolvimento econômico. O programa não atingiu as expectativas, alcançado um número menor de adesão ao financiamento do que era esperado, sendo um dos principais motivos para esse resultado a falta de recursos para elaboração do projeto e também o despreparo técnico, (FIEK E LOOSE 2017). 
No dia 05 de dezembro de 1996, foi criado o Simples, por meio da Lei n 9.317 o qual, incluía as empresas de pequeno porte e normatizava regras sobre o regime tributário, criando o sistema integrado de pagamentos de impostos e Contribuições para as Micro e Pequenas Empresas, o qual girava em torno de uma tabela progressiva de alíquotas que tinha como base o faturamento da empresa (PADOVEZE; MARTINS, 2014).

Em 05 de outubro de 1999 foi aprovada a Lei n 9.841, onde surgia o Estatuto da Microempresa e da Empresa de Pequeno Porte, revogando a Lei 8.864/1994, conhecida como Estatuto da Micro e Pequena Empresa. Em 14 de dezembro de 2006, foi aprovada a lei $n^{\circ} 123$, que instituiu o Estatuto Nacional da Microempresa e Empresa de Pequeno Porte, regulamentando o tratamento diferenciado as Micro e Pequenas empresas em vários aspectos revogando a lei n ${ }^{\circ} 9.841$ (PADOVEZE; MARTINS, 2014).

\section{Contabilidade gerencial}

A contabilidade gerencial pode ser definida como um conjunto de técnicas e procedimentos contábeis, como a contabilidade financeira, a de custos e a análise das demonstrações contábeis, que, quando combinados, fornecem informações valiosas para o processo de tomada de decisão nas empresas (CREPALDI, 2011).

Com a utilização da contabilidade gerencial, é possível também comparar a sua empresa com concorrentes e utilizar dados do mercado para entender melhor o contexto em que você está trabalhando, utilizando previsões e tendências para projetar o futuro de suas atividades e de seu negócio como um todo (SOUZA; REZENDE, 2017).

Nos empreendimentos existem diversas formas que podem ser utilizadas quando se busca um melhor gerenciamento das atividades. As informações predominantemente de cunho interno auxiliam o gestor no processo decisório proporcionando melhores resultados. $\mathrm{O}$ ambiente em que as empresas estão inseridas pode ser considerado hostil, e responder adequadamente, assim como também assegurar a manutenção do desempenho da empresa, é tarefa complexa, dado que as mudanças ocorrem de maneira rápida e constante (MORAIS; COELHO; HOLANDA, 2014).

Nesse contexto, o panorama onde diversas empresas, principalmente as pequenas, têm encerrado suas atividades ou enfrentam sérios problemas de sobrevivência, decorrentes de dificuldades na gestão, uma vez que utilizam a contabilidade apenas para atender as exigências fiscais. Uma das premissas fundamentais da informação contábil é contribuir para a tomada de decisão, de modo que as melhores práticas sejam adotadas pelos gestores. Essas informações são necessárias para todo tipo de organização (SANTOS; DOROV; BEUREN, 2016).

Santos, Dorow e Beuren (2016) consideram também, que as informações contábeis são necessárias para a tomada de decisão em todos os tipos de organizações, sendo que nos pequenos negócios a informação se torna vital para o processo de continuidade. Com isso, a Contabilidade Gerencial produz informações que permitirão uma tomada de decisão precisa e em conformidade com o objetivo empresarial, uma vez que a continuidade dos empreendimentos está associada aos resultados positivos que forem gerados (MOURA; PEREIRA; RECH, 2016).

Percebe-se assim a total importância da contabilidade gerencial na gestão de negócios em qualquer área de atuação ou porte da organização, pois representa uma fonte fundamental de informação em nível econômico e financeiro que auxilia os gestores no processo decisório. É por meio das informações geradas pela contabilidade gerencial que o gestor embasa suas decisões quanto à análise de orçamento empresarial, fluxo de caixa, análise das demonstrações contábeis, custos fixos e variáveis, margem de contribuição e Gecon, entre outras ferramentas (SOUZA; REZENDE, 2017).

Com o cenário econômico apresentado nos anos de 2015 e 2016 fica evidente que a cada dia mais se verifica a necessidade de uma eficaz administração, onde essa deva trazer resultados positivos para a empresa. Para tais resultados, o administrador deve estar amparado em suas decisões, onde possa ter a certeza de como está a situação da empresa e os caminhos que deva seguir. Neste sentido existe um ramo da contabilidade que tem os objetivos específicos fornecer informações aos administradores das empresas. Este ramo específico é conhecido como contabilidade gerencial (FIEK; LOOSE, 2017). 
Santos et al. (2017) comentam que os instrumentos da contabilidade gerencial podem ser utilizados por pequenas e médias empresas em suas atividades operacionais e gerenciais para auxiliar em tomadas de decisões. Assim, as empresas prestadoras de serviços contábeis deveriam contribuir com os conhecimentos necessários dessa área, fornecendo instrumentos gerenciais aos seus clientes, principalmente para empresas que não têm uma pessoa para executar a função de contador gerencial, facilitando o processo de tomada de decisão e contribuindo para o desempenho dos negócios.

\section{Estudos correlatos}

Os estudos correlatos apresentam a importância da contabilidade gerencial dentro de medias e pequenas empresas fazendo com que seus administradores tenham uma nova visão a respeito das informações obtidas.

Heinen e Soutes (2014) relatam em sua pesquisa feita em micro e pequenas indústrias cadastradas no Setor de Alvará da Prefeitura Municipal, totalizando 212 empresas com o objetivo de identificar quais as informações de natureza contábil são utilizadas pelas micro e pequenas indústrias da cidade de Marechal Cândido Rondon - Paraná. Também se buscou identificar o perfil destas indústrias e o perfil dos gestores. Os resultados apontam que as informações mais utilizadas na gestão do caixa são: o controle de caixa, monitoramento das contas a receber, controle das contas a pagar, consulta da área de compras à área financeira, análise de recursos a serem investidos em salários, análise da liquidez e da posição de caixa para planejar o volume e a maneira certa para distribuir lucros.

Em seu estudo Coelho (2015) demonstra em uma pesquisa feita dentro de uma mecânica de caminhões. O objetivo implantar um método que auxilie no equilíbrio do estoque de peças utilizadas em caminhões, nas realizações de serviços e reparos. Após a implantação das melhorias propostas, o estudo alcançou resultados que evidenciaram que a reorganização na gestão de estoque da referida empresa foi fundamental para a diminuição dos custos operacionais.

Fernandes e Galvão (2016) mencionam em seu estudo qualitativo das informações contidas em livros publicados pelos estudiosos e especialistas da área de controladoria, tais como: Figueiredo e Caggiano; Frezatti; Nascimento, Reginato e Oliveira entre outros, e também em sites de entidades de pesquisas e apoio às MPEs, como SEBRAEServiço Brasileiro de Apoio às Micro e Pequenas Empresas, IBGE-Instituto Brasileiro de Geografia e Estatística, IBPT-Instituto Brasileiro de Planejamento Tributário, Presidência da República-Casa Civil. O objetivo fazer uma reflexão sobre o uso da controladoria como ferramenta de gestão nas micro e pequenas empresas (MPEs), baseado em informações contidas em sites e em várias publicações de autores e especialistas da área Podendo-se concluir que os benefícios advindos da controladoria excedem os seus custos, pelo menos, a médio e longo prazo. Mesmo quando há escassez de recursos financeiros, as MPEs devem entender esse desembolso como um investimento importante para a empresa. Pois, o retorno poderá ser infinitamente superior, ao proporcionar crescimento e longevidade às empresas, desejo esse de todos que decidem empreender.

Magro, Silva e Klann (2017) por meio de uma pesquisa constituída de 78 empresas dos segmentos de bens industriais, consumo não-cíclico e materiais básicos tendo como objetivo verificar o efeito dos diferentes comportamentos estratégicos organizacionais sobre o comportamento oportunistas dos gestores em práticas de gerenciamento de resultados mediante escolhas contábeis. Chegando ao resultado que, em média, as empresas com estratégias defensoras gerenciam em menor proporção os resultados contábeis. As empresas com estratégias prospectora e analisadora apresentam maior propensão para o gerenciamento dos resultados com vista à obtenção de maiores lucros, enquanto as empresas com estratégias reativas apresentam maior nível de gerenciamento de resultados com a finalidade de reduzir os lucros.

Em estudo o realizado, Aires et al. (2018) exibe pesquisa feita em uma empresa familiar de pequeno porte com o objetivo de apresentar uma proposta de sistema de controle interno para uma empresa familiar de médio porte econômico. Os resultados das empresas pesquisadas evidenciaram que os controles internos mais utilizados por ambas foram nos departamentos "compras" e "pagamentos e folha de pagamentos". Com todos os dados obtidos, chegaram à conclusão que não é o porte da empresa que define a necessidade de sistemas de controle interno e que estes são eficientes na gestão das micro e pequenas empresas. 
Conforme estudo realizado Santos et al. (2018) em uma análise feita com 39 empresas clientes de uma empresa de serviços contábeis. Também foram entrevistados os dirigentes do escritório de contabilidade tendo com o objetivo averiguar o uso dos instrumentos de contabilidade gerencial em pequenas e médias empresas e o seu fornecimento pelo escritório de contabilidade. Chegando ao resultado de que, dos instrumentos de contabilidade gerencial disponibilizados pela empresa de serviços contábeis, predominam as demonstrações contábeis e o planejamento tributário. Entretanto, o maior uso pelos clientes concentra-se nos controles operacionais de gestão, como controle de contas a receber, controle de contas a pagar, entre outros, mas poucos dos instrumentos de contabilidade gerencial fornecidos pelo escritório de contabilidade são efetivamente utilizados pelas empresas pesquisadas.

Os estudos apresentados pelos pesquisadores destacam a importância do uso da utilização da contabilidade gerencial nas medias e pequenas empresas, esse instrumento e seu fornecimento de informações tem auxiliado seus administradores nas tomadas de decisões e ajudado em uma melhor administração.

\section{Procedimentos metodológicos}

A metodologia se caracteriza por descrever os procedimentos que serão seguidos para a realização da pesquisa, seguindo aspectos delimitados, ou seja, será a apresentação do passo a passo a ser utilizado na elaboração da pesquisa (GIL 2017).

A pesquisa se caracteriza como descritiva porque tem como objetivo descrever características de determinada população, fenômeno ou o estabelecimento de relações entre as variáveis, o estudo descritivo exige do pesquisador uma delimitação precisa de técnicas, métodos, modelos e teorias que orientarão a coleta e interpretação da coleta de dados, cujo objetivo é conferir validade cientifica a pesquisa. A população e amostra também devem ser delimitadas, assim como os objetivos, os termos, as variáveis, as hipóteses e as questões de pesquisa (BEUREN 2004).

Quanto aos procedimentos da pesquisa foi realizado um levantamento de dados através de questionários embasado no conteúdo da pesquisa, o questionário foi aplicado no período de 01 de julho de 2019 a 31 de agosto de 2019 sendo a população da pesquisa pequenas e médias empresas situadas no município de São Lourenço do OesteSC, com a finalidade de descobrir se essas empresas fazem o uso da contabilidade gerencial e frisar a importância de tal ferramenta na administração das empresas nos dias de hoje.

Quanto à abordagem do problema se classifica por quantitativa caracterizando se pelo emprego de instrumentos estatísticos, tanto na coleta quanto no tratamento dos dados. Marconi e Lakatos (2008) afirmam que o método quantitativo, diferenciando-se do método qualitativo, os pesquisadores terão como objetivo amostras amplas e informações numéricas, aplicando a elas técnicas estatísticas com ênfase na quantificação dos dados.

A população de pesquisa foi em pequenas e medias empresas situada na cidade de São Lourenço do Oeste e região, o questionário aberto foi enviado por e-mail e também foi feito pessoalmente pelo pesquisador nas 19 empresas selecionadas intencionalmente, no decorrer dos meses de julho a agosto de 2019.

As empresas foram selecionadas intencionalmente pelo porte que se enquadrassem como micro e pequenas empresas, não ultrapassando um faturamento anual de 4.800.000,00 de reais, e também pelo motivo de que em nossa cidade as várias empresas que se encaixam nesses requisitos.

Conforme Beuren et al. (2004) o questionário é um instrumento de coleta de dados constituído por uma serie ordenada de perguntas que devem ser respondidas por escrito pelo informante. Gil (2010) define o questionário como uma técnica de investigação composta por número mais o menos elevado de questões apresentadas por escrito as pessoas, tendo como objetivo o conhecimento de suas opiniões. O processo de elaboração dos questionários é um tanto quanto complexo e longo exigindo cuidado na seleção e formulação das questões. As perguntas devem ser claras, objetivas e ter linguagem de fácil interpretação e entendimento para o público alvo.

De acordo com Beuren et al. (2004) os questionários são enviados ao informante por e-mail ou por um portador, que, após o preenchimento, é devolvido do mesmo modo. Em referência aos tipos de questões podem ser abertas 
ou fechadas, as questões abertas, também são chamadas de livres e podem ao informante responder livremente, usando sua própria linguagem e emitir opiniões se necessário.

\section{Apresentação e análise dos resultados}

Esta pesquisa foi realizada por meio de questionário com instrumento de pesquisa desenvolvido por 17 questões embasada no estudo feito por Sottili, Maboni (2009) que visa coletar e analisar os dados obtidos para melhorar o desempenho tomadas de decisões através dessa ferramenta que é contabilidade gerencial.

Os estabelecimentos selecionados são de diversos ramos, tais como: distribuidora de gás e água; comércio de confecções, calçados e enxovais; comercio e serviços de autopeças; lojas de informática; restaurante; fabricação e instalação de móveis; panificadora; mercado; comércio de combustíveis; mecânica de automóveis; mecânicas de máquinas agrícolas; madeireira; comercio de materiais para construção; comercio de móveis e eletrodomésticos; loja de informática; distribuidora de bebidas; metalúrgica e tornearia mecânica.

Quadro 1: Ramo de Atividade das 19 Empresas Pesquisadas Pergunta 1: Indique o ramo de atividade da sua empresa:

\begin{tabular}{|l|c|}
\hline Comercio & $13 \%$ \\
\hline Industria e serviços & $7 \%$ \\
\hline Serviços & $40 \%$ \\
\hline Comercio e Serviços & $40 \%$ \\
\hline
\end{tabular}

Fonte: dados da pesquisa

No quadro 1 percebe-se que mais da metade das empresas questionadas são do ramo de serviços $40 \%$ e comercio e serviços $40 \%$ sendo apenas só $13 \%$ de comercio e $7 \%$ indústria e comercio.

No âmbito municipal a cidade na qual foi desenvolvido e aplicado o questionário tem um grande domínio no ramo de atividade de comercio e serviços no qual podemos perceber que foram nessas duas áreas que teve mais destaque, por ser uma cidade não muito grande os empresários optam por montar seus negócios em base no que a cidade necessita e no que traz mais benefícios para as empresas.

Quadro 2: Faturamento Bruto Mensal das 19 empresas pesquisadas Pergunta 2: Indique o faturamento bruto médio mensal:

\begin{tabular}{|l|c|}
\hline Até $\mathrm{R} \$ 30.000,00$ & $47 \%$ \\
\hline de $\mathrm{R} \$ 30.000,01$ a $\mathrm{R} \$ 50.000,00$ & $36 \%$ \\
\hline de $\mathrm{R} \$ 50.000,01$ a $\mathrm{R} \$ 70.000,00$ & $5 \%$ \\
\hline acima de $\mathrm{R} \$ 70.000,01$ & $12 \%$ \\
\hline
\end{tabular}

Fonte: dados da pesquisa

Constata-se na tabela 2 que quase metade das empresas pesquisadas possuem faturamento bruto mensal até $\mathrm{R} \$$ $30.000,00,45 \%$ apresentaram faturamento entre $\mathrm{R} \$ 30.001,00$ a $\mathrm{R} \$ 50.000,00$, e apenas $10 \%$ entre $\mathrm{R} \$ 50.001,00$ a $\mathrm{R} \$ 70.000,00$. Percebe-se que a maioria, por se tratar de micro e pequenas empresas, possuem um bom faturamento.

As empresas questionadas apesar de serem pequenas e nos mais variados ramos de atividade podemos considerar que possuem um bom faturamento, levando em consideração o tamanho da cidade na qual elas então instaladas, que não é de grande população, mas tem o no comercio e serviços e indústria um grande movimento fazendo com isso ajude no faturamento dessas empresas. 
Quadro 3: Área de mais Atenção na Contabilidade das 19 empresas pesquisadas Pergunta 3: Qual área da contabilidade recebe maior atenção?

\begin{tabular}{|l|c|}
\hline Financeira & $65 \%$ \\
\hline Tributária & $0 \%$ \\
\hline Custos & $7 \%$ \\
\hline Vendas & $28 \%$ \\
\hline
\end{tabular}

Fonte: dados da pesquisa

Percebe-se que mais de $60 \%$ das empresas questionadas tem mais preocupação na área financeira, por se tratar do departamento que administra os recursos da empresa além de fazer o planejamento financeiro da empresa. Em segundo lugar com $28 \%$ vem a parte das vendas, em seguida vem a área de custos com apenas 7\%. A parte tributária e de pessoal ainda não desperta o interesse dos empresários das empresas questionadas.

Observa-se que boa parte das empresas questionadas prestam mais atenção para área financeira da empresa, porque uma área que requer muita atenção pois é através dela que a empresas conseguem controlar de maneira mais eficaz as finanças da empresa, seja com relação à análise de investimentos, ao planejamento dos gastos e vendas, ao controle do estoque ou à concessão de crédito para clientes.

Dependendo de como for utilizada, essa é uma ferramenta que pode impulsionar ou até mesmo quebrar um negócio. Vale destacar também que $0 \%$ das empresas questionadas não sem importam com a parte tributaria isso é preocupante porque sabemos a importância que essa área tem dentro de uma empresa, área tributária é a parte da contabilidade que trabalha na administração dos tributos de uma empresa, ela não tem apenas o objetivo de manter os impostos organizados e em dia, mas também de viabilizar o negócio. Levar a contabilidade tributária a sério evita riscos de erros contábeis que possam levar a empresa a gastar mais em impostos, tornando o negócio menos viável.

Quadro 4: Contabilidade das 19 empresas pesquisadas Pergunta 4: Como é realizada a contabilidade das na sua empresa?

\begin{tabular}{|l|c|}
\hline Interna, feita na própria empresa, com funcionário próprio & $34 \%$ \\
\hline $\begin{array}{l}\text { Interna, feita na própria empresa, com funcionário } \\
\text { terceirizado (de outra empresa) }\end{array}$ & $0 \%$ \\
\hline Externa, feita em escritório de contabilidade & $66 \%$ \\
\hline
\end{tabular}

Fonte: dados da pesquisa

Percebe-se que $66 \%$ das empresas preferem a contabilidade externa sendo feita por um escritório de contabilidade, tendo como principal motivo a redução de custos e evitar transtornos na empresa, e seus profissionais forcar mais em suas atividades. Os outros $34 \%$ preferem a contabilidade interna, pois preferem um profissional que esteja presente em todas as atividades da empresa e para solucionar suas dúvidas com mais rapidez pois ele estará disponível em qualquer horário.

Vale destacar que a contabilidade feita internamente traz alguns benefícios para empresa tais como: a) planejamento tributário permanente; b) informações confiáveis e rápidas para auxiliar os gestores na tomada de decisões estratégicas; c) redução dos erros e atrasos no cumprimento das obrigações fiscais. A implantação da contabilidade interna não implica necessariamente no aumento de despesas para a empresa. Ao contrário, pode resultar em redução quando bem planejada.

Em seu estudo de Melo e Conte (2014) afirma-se que todas as entidades necessitam de um controle interno eficaz, para assim alcançar melhores resultados por meio de decisões baseadas em informações confiáveis. Sendo assim, nota-se a importância que a contabilidade gerencial tem para o andamento das empresas e para o gerenciamento de seus resultados. 
Quadro 5: Considera a contabilidade gerencial Pergunta 5: Como você considera a contabilidade gerencial?

\begin{tabular}{|l|c|}
\hline Ruim & $0 \%$ \\
\hline Razoável & $9 \%$ \\
\hline Boa & $73 \%$ \\
\hline Muito boa & $18 \%$ \\
\hline
\end{tabular}

Fonte: dados da pesquisa

Nota-se que $73 \%$ das empresas questionadas consideram a contabilidade gerencial muito boa, pois vem se tornando cada vez mais importante e decisiva na gestão empresarial, e seus profissionais fornecem muito mais do que apenas informações, muitas vezes eles assumem papel principal das decisões da empresa.

Quadro 6: Apresentação do resultado das questões 6 a 9

\begin{tabular}{|l|c|c|}
\hline \multicolumn{1}{|c|}{ Perguntas 6 a 9 } & Sim & Não \\
\hline 6. Conhece os benefícios da Contabilidade Gerencial? & $90 \%$ & $10 \%$ \\
\hline 7. Conhecendo os benefícios, implantaria na sua empresa? & $100 \%$ & $0 \%$ \\
\hline 8. Gostaria de ter os dados gerenciais mensalmente? & $65 \%$ & $35 \%$ \\
\hline 9. Gostaria de ter os dados gerenciais bimestralmente? & $65 \%$ & $35 \%$ \\
\hline
\end{tabular}

Fonte: dados da pesquisa

Das empresas questionadas apenas 10 responderam não conhecer a contabilidade gerencial. Porém $100 \%$ dessas empresas pesquisadas conhecendo os benefícios tem interesse em implantar a contabilidade gerencial em sua administração e $65 \%$ delas gostariam de ter os dados mensalmente por perceber que é uma ferramenta que pode auxiliar na gestão do negócio.

$\mathrm{Na}$ questão 9 foi indagado de que forma os empresários tomam as decisões gerencias em suas empresas. Foram citados vários métodos, tais como: "com base nas informaçôes repassadas pelo profissional responsável pela contabilidade da empresa"; "com base na atual e futura situação financeira da empresa"; "com base em reais conhecimentos sobre o problema e a situação da empresa"; "com base no relatório contábil e situação da empresa"; "com base nos relatórios financeiros"; com sabe nas informações prestadas pelos relatórios contábeis"; "com base na diferença do que compra e o que vende";

Analisando as respostas, percebe-se que a maioria dos empresários toma decisões gerenciais com base em relatórios financeiros. Conclui-se então, que os empresários que afirmaram conhecer a contabilidade gerencial não a endentem realmente, pois decisões gerenciais não são tomadas, apenas, com base em relatórios financeiros, mas sim com outras ferramentas, inclusive, as citadas neste trabalho.

Quadro 7: Formação preço de venda

\begin{tabular}{|l|l|}
\hline \multicolumn{2}{|c|}{ Pergunta 10: Como é formação de preço de venda na sua empresa? } \\
\hline Aplica um percentual sob o preço de compra & $70 \%$ \\
\hline Tem controle do custo e sob este aplica o percentual desejado & $16 \%$ \\
\hline Soma custos de produção e aplica um percentual em cima & $14 \%$ \\
\hline
\end{tabular}

Fonte: dados da pesquisa

Um total de $70 \%$ das empresas aplica um percentual sob o preço de compra do produto para formação de preço, com isso chegamos à conclusão que a grande maioria das empresas não conhecem os métodos certos pra tais funções, e muitos vezes acabam perdendo valor de venda por não saber calcular o preço correto de venda. 
Vale salientar que formação do preço de venda requer cuidado e atenção por parte dos administradores, a venda a valor excedente aos custos de compra e ou fabricação pode definir engano monetária de lucro. A formação do preço de venda deve trazer à empresa a maximização dos lucros; a conservação da qualidade, atendendo as necessidades do mercado àquele preço estipulado e que melhor empregue os níveis de produção.

Quadro 8: Análise de Indicadores da Empresa

\begin{tabular}{|l|c|}
\hline \multicolumn{2}{|c|}{ Pergunta 11: Como você analisa os números da sua empresa? } \\
\hline Nunca analisei & $5 \%$ \\
\hline Pelo total de faturamento & $90 \%$ \\
\hline Pelo total de compra & $5 \%$ \\
\hline Outro & $0 \%$ \\
\hline
\end{tabular}

Fonte: dados da pesquisa

Observa-se que $90 \%$ das empresas pesquisadas fazem a análise dos números das suas empresas através do faturamento, com isso elas conseguem perceber se é viável economicamente, possuírem estoques, sejam de materiais a serem processados ou de produtos acabados.

Analisar os números da empresa é de suma importância, através do quadro 8 percebe-se que quase 100\% das empresas estão analisando através do faturamento, pois o faturamento é peça essencial do funcionamento de uma empresa e deve ser feita com todo cuidado, conhecimento e treinamento possível para que não aconteça erros. Sua execução eficiente permite a tomada de decisões gerenciais e estratégicas adequadas, proporcionando aos gestores uma visão geral e ao mesmo tempo minuciosa da saúde financeira da empresa. O faturamento deve fornecer informações sobre consumidores, mercadorias, logística, transporte, prazos de entrega, pagamento entre outros dados que fazem a diferença na hora de vender um produto e planejar ações.

Quadro 9: Apresentação do resultado das questões 12 e 13

\begin{tabular}{|l|l|l|}
\hline \multicolumn{1}{|c|}{ Perguntas 12 e 13 } & Sim & Não \\
\hline 12. Contabilidade gerencial já foi oferecida para sua empresa & $51 \%$ & $49 \%$ \\
\hline $\begin{array}{l}\text { 13. Utilizou a contabilidade gerencial como instrumento para tomas alguma } \\
\text { decisão importante }\end{array}$ & $47 \%$ & $53 \%$ \\
\hline
\end{tabular}

Fonte: dados da pesquisa

Das empresas questionadas $51 \%$ responderam que a contabilidade gerencial já foi oferecida a empresa, sendo que $47 \%$ dessas empresas já usaram a contabilidade gerencial para tomar alguma decisão importante em sua administração. Mas observamos que $53 \%$ não utilizou da mesma ferramenta para tomada de decisões, com isso podemos perceber que há mais empresas que não sabem a importância da contabilidade gerencial para o dia a dia da empresa.

Em sua pesquisa Sottili e Maboni (2009) afirmaram que a contabilidade gerencial vem ganhando espaço no contexto sócio econômico, tem sido apontada como um dos principais instrumentos para auxiliar na gestão das empresas. Ela está voltada, exclusivamente, para a administração dos negócios, procurando fornecer informações válidas para a tomada de decisão de seus administradores. 
Quadro 10: Área da informação contábil de maior utilidade Pergunta 14: Indique a área que julgue a informação contábil tem mais utilidade:

\begin{tabular}{|l|c|}
\hline Fiscal & $48 \%$ \\
\hline Trabalhista & $0 \%$ \\
\hline Controle gerencial e tomadas de decisões & $49 \%$ \\
\hline Não sabe & $3 \%$ \\
\hline
\end{tabular}

Fonte: dados da pesquisa

Observa-se que 49\% das empresas que foi foram questionadas usam a informação contábil no controle gerencial e tomadas de decisões. Quem administra uma empresa conhece a necessidade de estar sempre por dentro de tudo que acontece nela. É preciso ter controle de estoques, fluxo de caixa e mantê-la funcionando da melhor forma possível. As informações contábeis ajudam a ter conhecimento de tudo que se passa em um negócio. O empresário ou gestor precisa estar a par de todas as funções de um relatório contábil. Além disso, precisa estar atento ao tipo de informação que ele traz e como pesquisar o que precisa nesse documento. Essa análise é simples e traz muito mais envolvimento com o responsável pela contabilidade, evitando erros e fraudes. Além de mostrar ao administrador a exata situação financeira em que a empresa está.

Quadro 11: Para que serve a contabilidade gerencial

\begin{tabular}{|l|c|}
\hline \multicolumn{2}{|c|}{ Pergunta 15: Na sua opinião, para que serve a contabilidade gerencial? } \\
\hline Tomada de decisões & $66 \%$ \\
\hline Controle financeiro & $34 \%$ \\
\hline Geração de impostos & $0 \%$ \\
\hline Não sei & $0 \%$ \\
\hline
\end{tabular}

Fonte: dados da pesquisa

Outro fator que se percebe e que teve a maioria das respostas com $66 \%$ das empresas respondendo que a contabilidade gerencial serve para tomadas de decisões. Tomar decisões em uma empresa nem sempre é fácil. Isso porque cada passo dado na direção errada pode refletir em prejuízos graves. Se não corrigidos a tempo, podem até mesmo resultar em falência. Entre todos os fatores que devem ser levados em consideração, a situação econômica da empresa se destaca.

A melhor forma de fazer isso é analisando as informações contábeis. Com esses relatórios em mãos, é possível fazer um planejamento de despesas e de crescimento. E até uma boa projeção de lucros com um investimento. Além disso, dá para saber se após colocar dinheiro em uma melhoria, sobrarão recursos se uma necessidade surgir de repente. Isso garante segurança nas decisões tomadas e mais eficiência nas previsões orçamentárias da empresa. Esse é considerado um hábito saudável de empresários que desejam crescer. A verdade é que, em um mercado atribulado como o atual, um empresário não pode se arriscar a dar tiros no escuro. Investir mais dinheiro do que pode ou comprometer o orçamento que seria utilizado para pagar compromissos são riscos desnecessários que uma empresa não pode correr se quiser crescer e se manter no mercado.

Ir atrás de conhecimento para tomar decisões não é só uma orientação, é uma necessidade e uma obrigação. Com os dados contábeis corretos em mãos, é muito mais fácil e eficiente refletir sobre qual decisão tomar e o que será melhor para empresa naquele momento. Consequentemente, os caminhos que a empresa precisa seguir para obter suas metas e alcançar seus objetivos. 


\section{Considerações finais}

Atualmente, as micro empresas e empresas de pequeno porte sofrem muitas mudanças, necessitando de ferramentas e informações contábeis que possam auxiliá-las em suas decisões gerenciais à cerca de que essas lhes sirvam de base para melhor administração da empresa e ajudar em quais decisões tomar. Visando dar suporte e auxiliar a empresas nesses quesitos, esse trabalho teve como objetivo abordar a contabilidade gerencial e o uso desta pelas micro e pequenas empresas, verificando a importância das informações geradas para administração e tomada de decisão.

Com base na pesquisa por meio de questionário observa-se que a contabilidade gerencial pode auxiliar na gestão das micro e pequenas empresas, já que o usuário pode moldá-la de acordo com a sua necessidade de informação possuindo, assim, uma visão mais clara da empresa.

Entre as ferramentas da contabilidade gerencial, as consideráveis indispensáveis para uma boa administração, de acordo com a pesquisa feita, são as seguintes: a) os controles internos e externos, que podem fornecer relatórios e análises precisas, onde demonstram a situação da organização; b) formação de preço de venda, pois é um fator determinante para o sucesso da empresa em um mercado competitivo; c) as análises das demonstrações contábeis, que podem propiciar avaliações do patrimônio e das decisões tomadas, tanto em relação ao passado quanto em relação ao futuro aumentando, assim, a segurança nas decisões do empresário.

Foi aplicado perguntas com objetivo de identificar o conhecimento dos empresários sobre a contabilidade gerencial, seus benefícios e sua importância para a gestão do negócio. Entre as empresas entrevistadas foi verificado que a maioria dos empresários possui o conhecimento sobre as ferramentas e o benefício que a contabilidade gerencial pode oferecer, e que mais da metade dos perguntados gostariam de ter os dados gerencias ou mensalmente ou bimestralmente, pode-se chegar a tal conclusão das repostas obtidas através do questionário.

Por meio dos dados obtidos verificou-se que a maioria das empresas questionadas usam as ferramentas gerenciais para tomadas de decisões, e que dão mais atenção para área financeira que é de suma importância, mas por outro lado não estão dando atenção devida para a área tributária que juntamente com a financeira são as duas áreas que se deve dar mais atenção dentro de uma empresa. Percebe-se através da pesquisa feita que as empresas preferem a contabilidade externa feita por um escritório contábil, um dos fatores para essa escolha é redução de gastos.

Percebe-se que através dos questionários que para mais da metade das empresas questionadas de algum momento a contabilidade gerencial já foi oferecida e boa parte já utilizou dessa ferramenta como instrumento para uma importante ação dentro da empresa, seja para tomada de decisões ou para melhora a gestão da empresa, e com o questionário constatou-se que todas as empresas estão satisfeitas com a informações que veem recebendo de seus contadores ou responsáveis pela contabilidade da empresa.

Esta pesquisa destacou a importância das empresas de pequeno porte no contexto socioeconômico, pois são fonte geradoras de emprego e riqueza, aumentando a economia e a competividade. Cada vez mais tem papel fundamental na economia brasileira, e é o segmento gerador de empregos. Destacou-se também a importância de as empresas utilizarem contabilidade gerencial como ferramenta na sua gestão e tomada de decisões.

Por meio deste estudo sugere-se para pesquisas futuras que a contabilidade gerencial seja mais evidenciada ao meio empresarial, para que se torne uma ferramenta de gestão indispensável a todo empresário. Sugere também estreitar o laço entre contabilidade gerencial e o meio empresarial por estudos que simplifiquem as rotinas das empresas e assim auxiliando os empresários na administração da empresa, aumentando o conhecimento dentro de uma organização para ajudar a tomar decisões e manter um controle eficaz sobre os recursos da empresa. 


\section{Referências}

ALMEIDA, D. M.; PEREIRA, I. M.; LIMA, I. J. Instrumentos de Controle de Gestão utilizados por Micro e Pequenas Empresa Sul Catarinenses. Revista da Micro e Pequena Empresa, v. 10, n. 3, p. 49-92, 2016.

AYRES, L. C. N.; CRUZ, V. L.; SANTOS, R. R. D.; LEONE, R. J. G. Controle Interno em Empresas Familiares de Pequeno Porte: Uma Aplicação do Modelo COSO II. Revista da Micro e Pequena Empresa, v. 12, n. 1, p. 3-17, 2018.

BARRETO, P. S.; DA SILVA MACEDO, M. A.; DOS SANTOS ALVES, F. J. Análise do comportamento decisório frente à influência dos efeitos certeza e framing no ambiente contábil. Registro Contábil, v. 4, n. 3, p. 39-55, 2013.

BEUREN, ILSE MARIA. Como elaborar trabalhos monográficos em contabilidade: teoria e prática. 2 ed. São Paulo: Atlas, 2004.

CALladO, A. A. C.; MELO, W. A. Ferramentas e Informações Gerenciais em Micro e Pequenas Empresas. RAUnP - Revista Eletrônica do Mestrado Profissional em Administração da Universidade Potiguar, v. 10, n. 3, p. 53-65, 2018.

COELHO, M. P; NASCIMENTO, C. O. Planejamento e controle de estoque: um estudo de caso em uma empresa de mecânica para caminhões pesados, UniRV - Universidade de Rio Verde, 2015.

CREPALDI, SILVIO APARECIDO. Contabilidade gerencial: teoria e prática. 5. ed. São Paulo: Atlas, 2011.

FERNANDES, A. M.; GALVÃO, P. R. A Controladoria como ferramenta de gestão nas micro e pequenas empresas: um estudo da viabilidade e da relação custo benefício. Revista de Tecnologia Aplicada, v. 5, n. 1, p. 3-16, 2016.

FIEK, Nilton; LOOSE, Cleberson Eller. (2017) Uso das informações contábeis nas micro e pequenas empresas. Revista de Administração de Roraima - RARR, Boa Vista, Vol. 7 n. 2, p.348-365, jul-dez. 2017. Disponível em: $<$ http://revista.ufrr.br/index.php/adminrr/>. Acesso em: 27 de junho de 2019.

GIL, A. C. Como elaborar projetos de pesquisa. 5. ed. São Paulo: Atlas, 2017.

HEINEN, L. B.; SOUTES, D. O. Informações de natureza contábil e gestão do caixa: Um levantamento sobre sua utilização pelas micro e pequenas indústrias de Marechal Cândido Rondon (PR). Revista Mineira de Contabilidade, v. 3, n. 55, p. 32-42, 2014.

LAKATOS, EVA MARIA.; MARCONI, MARIA ANDRADE.( 2008). Metodologia científica. 5. ed. São Paulo: Atlas.

MAGRO, C. B. D.; SILVA, T. B. J.; KLANN, R. C. Comportamento Estratégico Organizacional e a Prática de Gerenciamento de Resultados nas Empresas Brasileiras. Revista Ibero-Americana de Estratégia, v. 16, n. 1, p. 119-137, 2017.

MELO, Ediane Daiane Ramos de; CONTE, Paula Zanchet; DEDONATTO, Omeri. Controles gerenciais para uma empresa de pequeno porte prestadora de serviço de manutenção industrial. 2014. Monografia (conclusão do curso de Ciências Contábeis) - Universidade Comunitária da Região de Chapecó, 2014. Disponível em: $<$ http://fleming.unochapeco.edu.br:8080/pergamumweb/vinculos/0000cf/0000cf7e.pdf $>$. Acesso em: 12 de novembro de 2019.

MORAIS, O. O., COELHO, A. C. D.; HOLANDA, A. P. (2014). Artefatos de contabilidade gerencial e maximização do valor em firmas brasileiras. Revista de Contabilidade \& Controladoria. UFPR. Curitiba-PR, v. 6, n. 2, p. 128-146, maio/ago.

MOURA, M. F., PEREIRA, N. A. \& RECH, I. (2016). Análise quanto ao uso de ferramentas e informações gerenciais pelos produtores de gado de corte. Revista Evidenciação Contábil \& Finanças, João Pessoa, v. 4, n. 3, p. $72-88$, set./dez. 
REZENDE, ANDRÉ LUÍS LOPES; SOUZA, FRANCISCO JOHN CARVALHO. A importância da contabilidade gerencial para as micro e pequenas empresas: estudo de caso na microempresa el shaday baby. Revista de Administração e Contabilidade-RAC, v. 3, n. 5, 2016.

SEBRAE. Serviço Brasileiro de Apoio às Micro e Pequenas Empresas. Micro e pequenas empresas geram 27\% do PIB do Brasil. 2014. Disponível em: $<$ http://www.sebrae.com.br/sites/PortalSebrae/ufs/mt/noticias/micro-e-pequenas-empresas-geram-27-dopib-do-brasil,ad0fc70646467410VgnVCM2000003c74010aRCRD >. Acesso em: 26 de abril de 2019.

SEBRAE-SC - Serviço Brasileiro de Apoio às Micro e Pequenas Empresas de Santa Catarina. Critérios de avaliação de empresas: MEI, ME, EPP. Disponível em: <http://www.sebraesc.com.br/leis/default.asp?vcdtexto=4154>. Acesso em: 25 de abril de 2019.

SANTOS, V., DOROW, D. R. \& BEUREN, I. M. (2016). Práticas gerenciais de micro e pequenas empresas. Revista Ambiente Contábil, v. 8, n. 1, jan./jun. ISSN 2176-9036.

SANTOS, V. D.; BENNERT, P.; FIGUEIREDO, G. H.; BEUREN, I. M. Uso dos Instrumentos de Contabilidade Gerencial em Pequenas e Médias Empresas e seu Fornecimento pelo Escritório de Contabilidade. Pensar contábil, v. 20, n. 71, p. 53-67, 2018.

SOTILLI, F.; MABONI, S. M. Contabilidade gerencial, o uso da informação gerencial numa pequena empresa. 2009. Disponível em: < http://revistas.utfpr.edu.br/pb/index.php/ecap/article/download/777/425 >. Acesso em: 26 de junho de 2019.

PADOVEZE, C. L.; MARTINS, M. A. Contabilidade e Gestão para micro e pequenas empresas. 1. ed. Curitiba: Intersaberes, 2014..

VAZ, P. V. C.; ESPEJO, M. M. D. S. B. Do texto ao contexto: o uso da contabilidade gerencial pelas pequenas empresas sob a perspectiva teórica de Bakhtin. Revista de Contabilidade e Organizações, v. 9, n. 24, p. 31-41, 2015. 